\title{
CHARACTERIZATION OF SOLID POLYMER ELECTROLYTES BASED \\ ON POLY(TRIMETHYLENECARBONATE) AND LITHIUM \\ TETRAFLUOROBORATE
}

\author{
Maria Manuela Silva ${ }^{\mathrm{a}}$, Sandra Cerqueira Barros ${ }^{\mathrm{a}}$, Michael J. Smith ${ }^{\mathrm{a}^{*}}$ and \\ James R. MacCallum ${ }^{b}$ \\ ${ }^{a}$ Centro de Química, Universidade do Minho, 4710-320 Braga, Portugal \\ ${ }^{\mathrm{b}}$ School of Chemistry, University of St. Andrews, St. Andrews, United Kingdom
}

\begin{abstract}
The results of an investigation of a polymer electrolyte system based on the poly(trimethylene carbonate) host matrix, designated as $\mathrm{p}(\mathrm{TMC})$, with lithium tetrafluoroborate guest salt are described in this presentation. Electrolytes with lithium salt compositions with $\mathrm{n}$ between 3 and 80 (where $\mathrm{n}$ represents the number of $\left(\mathrm{O}=\mathrm{COCH}_{2} \mathrm{CH}_{2} \mathrm{CH}_{2} \mathrm{O}\right)$ units per lithium ion) were prepared by co-dissolution of salt and polymer in anhydrous tetrahydrofuran. The homogeneous solutions obtained by this procedure were evaporated, within a preparative glovebox and under a dry argon atmosphere, to form thin films of electrolyte.
\end{abstract}

The solvent-free electrolyte films produced were obtained as very flexible, transparent, completely amorphous films and were characterized by measurements of total ionic conductivity, cyclic voltammetry, differential scanning calorimetry and thermogravimetry. Keywords: polymer electrolytes; lithium tetrafluoroborate; conductivity; thermal stability

\footnotetext{
* Corresponding author. Fax: +253 678983, Phone: + 253 604051, Email address: mjsmith@quimica.uminho.pt
} 


\section{Introduction}

Since the introduction of the solid polymer electrolyte (SPE) concept in 1978 [1] studies of members of this sub-class of ionically conducting solids have been reported by many authors [2-6]. The results of the extensive characterization of the first generation of electrolytes based on poly(ethylene oxide), (PEO), or hosts with similar chemical structures, and a great variety of guest salt species, confirmed that many factors, including the choice of electrolyte components, preparative conditions and thermal history, determine the electrochemical, thermal and mechanical properties of the electrolyte system.

While other technological applications have been proposed, the principal motivation for continued interest in SPEs is the belief that these materials may be developed as components of advanced primary or secondary cells. To be successful candidates in this application electrolytes must be compatible with electrode materials, both mechanically and electrochemically, pass stringent safety tests and have low production costs. The original solvent-free or "dry" polymer electrolytes based on semi-crystalline host matrices were somewhat limited, particularly in relation to the mechanical properties and levels of ionic conductivity observed at low to moderate operating temperatures. Attempts to develop novel polymer electrolytes with improved conductivity were based on various strategies. As the most promising results had been obtained with amorphous host polymers incorporating the $-\mathrm{CH}_{2} \mathrm{CH}_{2} \mathrm{O}$ - repeat unit, many authors concentrated their attention on the synthesis of novel hosts incorporating the ethylene oxide moiety but with lower glass transition temperatures than that of the semi-crystalline homopolymer. The low dielectric constant of polymers based on this structure was recognized as a disadvantage [7] and more readily dissociated salts were developed $[8,9]$ to prepare electrolytes. The use of plasticizing additives has been extensively investigated [10-15], with the multiple objectives of facilitating polymer segment mobility, increasing the dielectric constant of the host medium or simply improving the mechanical properties of the electrolyte. The relationship between plasticizer content and conductivity is unfortunately not straightforward and it has also been suggested that the conductivity mechanism may change with additive content [16]. The addition of large amounts of plasticizer results in the formation of gels rather than SPEs. Cells based on electrolytes with 
such high liquid content benefit from high ionic conductivity but can suffer from the same disadvantages of electrolyte leakage [17] or undesirable reactions with electrode materials which solid electrolytes were introduced to avoid.

Certain plasticizing additives [10], and indeed some of the liquid electrolytes used in lithium ion cells $[18,19]$, incorporate the carbonate entity. This observation led us to study polycarbonates as host matrices. Exploratory studies of $\mathrm{p}(\mathrm{TMC}) / \mathrm{lithium}$ triflate and $\mathrm{p}(\mathrm{TMC}) /$ lithium perchlorate systems [20] confirmed that this host matrix solubilized lithium salts and sustained ionic conductivity of encouraging levels. In this paper we describe the thermal and electrochemical behavior of novel polymer electrolytes prepared by the incorporation of lithium tetrafluoroborate into the poly(trimethylene carbonate) host matrix.

\section{Experimental section}

\subsection{Materials}

High molar mass p(TMC) (3 x $10^{5}$ g.mol-1), prepared by catalyzed bulk polymerization and characterized by gel permeation chromatography, was provided by Shell Chemicals, Houston, TX, USA. The host polymer, obtained as a transparent amorphous elastomer, was dried before use at $70^{\circ} \mathrm{C}$, with argon/vacuum purge cycles, for a period of about 7 days. No further purification of the host polymer was carried out. Lithium tetrafluoroborate (Aldrich, 95\%), provided as a pure, dry solid, packed under nitrogen, was used as received. All subsequent manipulations of salt, electrolyte sample preparations and measurements were carried out within dry argon-filled gloveboxes.

\subsection{Sample preparation}

Homogeneous solutions of $\mathrm{p}(\mathrm{TMC})$ and lithium tetrafluoroborate in THF (Aldrich, anhydrous $99.9 \%$, inhibitor-free) were prepared by adding known masses of polymer and lithium salt to a conical flask. A convenient volume of THF was added as solvent and the contents of the flask were stirred for a period of at least 48 hours within a dry argon-filled preparative glovebox. The resulting homogeneous viscous solutions were decanted into glass rings seated on glass plates and the solvent was removed slowly in an isolated chamber within 
the preparative glovebox. The atmosphere of this chamber was recirculated through a column of molecular seives to effect a slow evaporation of THF and form films of about $150 \mu \mathrm{m}$ thickness. These electrolyte films were subjected to a final drying procedure in which the temperature was raised from $30^{\circ} \mathrm{C}$ to $60^{\circ} \mathrm{C}$ over a period of 3 days. During this period the tube oven was periodically evacuated and purged with dry argon.

\subsection{Measurements}

Total ionic conductivities of electrolyte samples were determined using a constant volume support [20] with gold blocking electrodes located within a Buchi TO 50 oven. The sample temperature was evaluated by means of a type $\mathrm{K}$ thermocouple placed close to the electrolyte film and impedance measurements were carried out at frequencies between $96 \mathrm{kHz}$ and $500 \mathrm{mHz}$ with a Solartron 1250 FRA and 1286 ECI, over a temperature range of 20 to $90^{\circ} \mathrm{C}$. Measurements of conductivity were effected during heating cycles. The reproducibility of recorded conductivities was confirmed by comparing the results obtained for a sample subjected to two heating-cooling-heating cycles. This procedure demonstrated the correct operation of the support and the mechanical stability of the samples.

Polymer electrolyte sections were removed from dry films and subjected to thermal analysis under a flowing argon atmosphere between -40 and $350^{\circ} \mathrm{C}$ and at a heating rate of $5^{\circ} \mathrm{C} \cdot \mathrm{min}^{-1}$ using a Mettler DSC 821e. All samples were presented for analysis in $40 \mu \mathrm{L}$ aluminium cans with perforated lids to permit the release of decomposition products.

Samples for thermogravimetric studies were prepared in a similar manner, transferred to open platinum crucibles and analyzed using a Rheometric Scientific TG 1000 thermobalance operating under a flowing argon atmosphere. A heating rate of $10^{\circ} \mathrm{C} \cdot \mathrm{min}^{-1}$ was used to analyze all the electrolyte samples.

Evaluation of the electrochemical stability window of electrolyte compositions was carried out using a two-electrode cell configuration. The cell was assembled by locating a lithium disk (Aldrich, 99.9\%, 10mm diameter, $1 \mathrm{~mm}$ thick) on a stainless steel current collector, placing a disk of electrolyte over the counter electrode, and supporting a $25 \mu \mathrm{m}$ 
diameter gold working electrode in contact with the electrolyte. The preparation of the microelectrode surface by the conventional polishing procedure was completed under dry argon. The experimental assembly was supported by using a suitable clamp to maintain good mechanical contact between the components during data acquisition. Measurements were conducted at room temperature within a dry argon-filled glovebox. An Autolab PGSTAT-12 (Eco Chemie) was used to record voltammograms.

\section{Results and discussion}

\subsection{Thermal analysis}

Differential scanning calorimetric analysis of samples removed from electrolyte films prepared with a range of salt content confirmed that the transparent flexible films contained no crystalline phases. While the thermal stability of the $\mathrm{p}(\mathrm{TMC})$-based electrolytes is generally significantly lower than that of compositions containing the ethylene oxide entity [20-23], the polycarbonate matrix has adequate stability for use in primary or secondary cells operating at ambient or close-to-ambient temperatures. A typical thermogram illustrating the behavior in the range of temperature where sample decomposition is observed is included in Figure 1 a). The characteristic irregularity of heat flux $[22,24]$ associated with thermal degradation is clearly visible in the thermogram obtained with the $\mathrm{p}(\mathrm{TMC})_{10} \mathrm{Li} \mathrm{BF}_{4}$ sample. In electrolytes containing lithium tetrafluoroborate the heat flux is, in certain cases, so irregular that the extrapolation to baseline procedure used to determine the onset of decomposition is difficult to apply. The second thermogram illustrated in Figure $1 \mathrm{~b}$ ) was recorded with $\mathrm{p}(\mathrm{TMC})_{10} \mathrm{Li} \mathrm{ClO}_{4}$. In this case the guest salt causes a violent exotherm in the latter stage of degradation. The use of lithium tetrafluoroborate rather than lithium perchlorate as an electrolyte component offers a clear advantage in relation to device safety. The variation of the temperature of onset of degradation with the salt composition is indicated in Figure 2a). 
As expected from previous studies of polycarbonate-based systems [20], the presence of high salt content in the electrolyte causes a decrease in the thermal stability of the electrolyte.

As the polymer chain segment mobility is directly related to the mechanical and conductivity performance of polymer electrolytes, the glass transition temperature, $\mathrm{Tg}$, of the electrolyte composition is a parameter which provides information which is useful in understanding the behavior of electrolyte systems. The variation of onset of Tg with $\mathrm{p}(\mathrm{TMC})_{\mathrm{n}}$ Li $\mathrm{BF}_{4}$ electrolyte composition is also illustrated in Figure $2 \mathrm{~b}$ ). It is interesting to note that the decrease of $\mathrm{Tg}$ with increase in salt content is similar to that previously observed in studies of an electrolyte based on the PEO host matrix with the same guest salt [25]. The suppression of crystallinity of the host polymer as a result of the addition of guest salt is commonly observed in electrolytes based on PEO. In certain cases the presence of the guest salt may also contribute a plasticizing effect, lowering the $\mathrm{Tg}$ of the host polymer. While various explanations have been proposed to account for the effect of plasticizing additives on the behavior of polymers [26], the free-volume theory is the most widely accepted. In accordance with this theory the presence of plasticizers in polymers increases the free-volume available to polymer chain segments and therefore allows greater internal chain rotation and an increase in the segment mobility. As the ion transport mechanism in solvent-free polymer electrolytes is dependant on the local motion of polymer segments, components which increase free volume may be expected to have a beneficial influence on conductivity. The result of the addition of lithium tetrafluoroborate to the electrolyte composition leads us to conclude that in this system the guest salt exerts a plasticizing effect on the polymer structure.

A further increase in salt content, beyond the salt composition associated with the electrolyte with lowest $\mathrm{Tg}$, results in an increase in polymer rigidity. This is in agreement with the behavior observed in several electrolyte systems where the interactions between the 
cations and polar segments belonging to different polymer chains cause ionic crosslinking which impedes segmental mobility and shifts the Tg of the electrolyte to higher temperatures.

\subsection{Ionic conductivity}

The results obtained from the conductivity measurements carried out on electrolytes over the temperature range from 25 to $90^{\circ} \mathrm{C}$ and with salt compositions between $\mathrm{n}=80$ and $\mathrm{n}$ $=3$ are shown in Figure 3. The conductivity isotherms derived from these results are also included in Figure 4 and confirm that the electrolyte system based on this guest salt behaves in a manner similar to that reported for the lithium perchlorate and lithium triflate systems. In all three electrolyte systems the conductivity increases with the salt content as the number of charged species available to support ionic conduction is increased and the $\mathrm{Tg}$ of the material decreases [20]. The importance of polymer segment mobility in this class of electrolytes has long-since been recognized as a critical factor [27] in determining conductivity performance. The fact that the conductivity of the $(\mathrm{TMC})_{\mathrm{n}} \mathrm{Li} \mathrm{BF}_{4}$ electrolyte system reaches a maximum (approximately $3 \times 10^{-4} \Omega^{-1} \mathrm{~cm}^{-1}$ at $95^{\circ} \mathrm{C}$ ) at the composition of $\mathrm{n}=4$, also associated with the minimum value of $\mathrm{Tg}$, suggests that it is indeed this factor that determines the conductivity behavior of this system. A further increase in salt content causes a reduction in conductivity. The presence of a conductivity maximum in conventional PEO-based electrolytes is explained in terms of the existence of a critical composition in which the morphological conditions and the ionic environment of the electrolyte are optimized for ionic transport. Electrolytes based on the $\mathrm{p}(\mathrm{TMC})$ host benefit from the characteristic of complete amorphicity over the entire composition range. This effectively means that even at very high salt content neither phase separation nor complex formation occurs to inhibit the ion transport process. With the (TMC) $\mathrm{Li} \mathrm{BF}_{4}$ electrolyte the limit to practical lithium content may indeed be imposed by moderate thermal stability rather than the morphological behavior of the material.

Another aspect of the $(\mathrm{TMC})_{\mathrm{n}} \mathrm{Li} \mathrm{BF}_{4}$ electrolyte behavior, common to all electrolytes based on this host polymer, is the sudden decrease in conductivity when the salt content is increased beyond the value associated with the optimum electrolyte composition. This effect may be explained in terms of the attraction which ions present in an inter-chain location 
exercise simultaneously on segments which belong to adjacent polymer chains. The formation of transient ion-polymer crosslinks would be expected to restrict segment mobility and therefore reduce conductivity. An alternative explanation is based on the formation of ion pairs or aggregates. The $\mathrm{p}(\mathrm{TMC})$ host has a fairly low dielectric constant, similar to that observed in PEO, and consequently as the guest salt concentration is increased a concomitant increase in the proportion of associated ions would be expected to be occur. These aggregates naturally contribute less effectively to charge transport and eventually hinder ion mobility at low values of $n$.

\subsection{Electrochemical stability}

Polymer electrolytes intended for practical applications in commercial devices must support high lithium ion mobility to provide elevated power densities in batteries or rapid response in sensors or optical displays. However, electrolytes must also be chemically stable to enable devices to attain extensive shelf lives and in high voltage devices they must be able to withstand the range of potential of the electrode couple. Figure 5 shows a typical voltammogram of a $(\mathrm{TMC})_{4} \mathrm{Li} \mathrm{BF}_{4}$ electrolyte sample. This data was recorded during the second scan from $0 \mathrm{~V}$ to the anodic decomposition limit at approximately $4.5 \mathrm{~V}$. A small anodic peak was observed at a potential consistent with the stripping of lithium [28] deposited at the cathodic limit of the first scan. The cathodic peak at about $3.8 \mathrm{~V}$ has been attributed to the reduction of a decomposition product. The stability of this novel electrolyte system is therefore considered adequate for application in lithium primary and secondary cells.

\section{Conclusion}

The $\mathrm{p}(\mathrm{TMC})$ host matrix has been shown to provide a suitable basis for the preparation of SPE materials incorporating a variety of guest salt species and to result in solvent-free electrolytes with encouraging conductivity behavior. In the most recent member of this series of electrolytes based on lithium tetrafluoroborate, the ionic conductivity attains a level which is comparable to the best composition of the (TMC) $)_{\mathrm{n}} \mathrm{Li} \mathrm{ClO}_{4}$ system, a value which is 
nevertheless significantly lower than the values reported for certain amorphous electrolytes containing the oxyethylene structural unit. In compensation, the new electrolyte based on the tetrafluoroborate salt has improved thermal stability relative to the perchlorate guest species, excellent mechanical properties and is perceived as an inherently safer cell component.

Although the search for solid electrolytes with appropriate characteristics for application in all-solid-state primary and secondary cells continues to be focussed on improving the total ionic conductivity of candidate materials, in practical cells other aspects of electrolyte performance assume similar levels of importance. An increase in the power output of a practical cell may be achieved by increasing the electrode/electrolyte interfacial area or by reducing the electrolyte thickness [29]. Clearly superior mechanical properties may to some extent compensate for a less adequate conductivity performance. Chemical and electrochemical compatibilities of the electrolytes, relative to the electrode materials, are essential and are dependent on all the electrolyte components. The $\mathrm{p}(\mathrm{TMC})$ polymer host described in this paper has not been extensively characterized, but preliminary assessment of prototype primary cells suggest that the macromolecular matrix has an adequate stability performance, even under the non-optimum conditions used in exploratory studies. To some extent this behavior might be predicted from previous assessment of acyclic alkyl carbonates $[18,19]$ as single solvents for Li-ion cell electrolytes. The materials introduced in this presentation are clearly still at a preliminary stage in their development and further characterization, including detailed studies of electrochemical stability and the behavior of prototype cells based on optimized electrolyte compositions, is certainly necessary to determine the extent to which their potential may be realized.

\section{Acknowledgements}

The authors are pleased to acknowledge the financial support provided by Shell Chemicals Limited, the Fundação para Ciência e Tecnologia and the Fundação Calouste 
Gulbenkian. The provision of laboratory facilities by the CQ research centre of the University of Minho and the School of Chemistry of the University of St. Andrews, is also gratefully acknowledged.

\section{References}

1. M. B. Armand, J. M. Chabagno, M. J. Duclot, Book of abstracts, 2nd International Conference on Solid Electrolytes, St. Andrews, Scotland, 20-22 Sept., 1978.

2. J. R. MacCallum, C. A. Vincent, Polymer Electrolyte Reviews, vol. 1 and 2, Elsevier, London, 1987 and 1989.

3. F. M. Gray (Ed.), Solid Polymer Electrolytes: Fundamentals and Technological Applications, VCH Publishers, New York, 1991.

4. B. Scrosati, Applications of Electroactive Polymers, Chapman and Hall, London, 1993.

5. R. G. Linford (Ed.), Electrochemical Science and Technology of Polymers, vol. 1 and 2, Elsevier, Amsterdam, 1987 and 1991.

6. F. M. Gray, Polymer Electrolytes, RSC Materials Monographs, Royal Society of Chemistry, London, 1997.

7. J. R. MacCallum, A. S. Tomlin, C. A. Vincent, Eur. Poly. J. 22 (1986) 787.

8. D. Benrabah, J.Y. Sanchez, M. Armand, Electrochim. Acta 37 (1992) 1737.

9. C. S. Kim, S. M. Oh, Electrochim. Acta 46 (2001) 1323.

10. M. S. Michael, M. M. E. Jacob, S. R. S. Prabaharan, S. Radhakrishna, Solid State Ion. 98 (1997) 167.

11. M. Alamgir, K. M. Abraham, in G. Pistoia (Ed.), Lithium Batteries, Elsevier, Amsterdam, 1994, Ch. 3.

12. J. M. G. Cowie, G. H. Spence, Solid State Ion. 109 (1998) 139.

13. T. Osaka, T. Momma, H. Ito, B. Scrosati, J. Power Sources 68 (1997) 392.

14. Y. Aihara, M. Kodama, K. Nakahara, H. Okise, K. Murata, J. Power Sources 65 (1997) 143.

15. S. Chintapalli, R. Frech, Solid State Ion. 86 (1996) 341. 
16. F. Croce, S. D. Brown, S. Greenbaum, S. M. Slane, M. Salomon, Chem. Mater. 5 (1993) 1268.

17. C. S. Kim, S. M. Oh, Electrochim. Acta 46 (2001) 1323.

18. G. Y. Gu, S. Bouvier, C. Wu, R. Laura, M. Rzeznik, K. M. Abraham, Electrochim. Acta 45 (2000) 3127.

19. I. Geoffroy, A. Chagnes, B. Carré, D. Lemordant, P. Biensan, S. Herreyre, J. Power Sources $112(2002) 191$.

20. M. J. Smith, M. M. Silva, S. Cerqueira, J. R. MacCallum, Solid State Ion. 140 (2001) 345.

21. C. J. R. Silva, M. J. Smith, Solid State Ion. 40 (1995) 2389.

22. L. Costa, A. M. Gad, G. Camino, G. G. Cameron, M. D. Ingram, M. Y. Qureshi, in: B. Scrosati (Ed.), Proceedings of the $2^{\text {nd }}$ International Symposium on Polymer Electrolytes, Elsevier, Amsterdam, 1990, p 49.

23. G. K. Jones, G. C. Farrington, A. R. McGhie in: B. Scrosati (Ed.), Proceedings of the $2^{\text {nd }}$ International Symposium on Polymer Electrolytes, Elsevier, Amsterdam, 1990, p 239.

24. M. Jaffe, J. D. Menczel, W. E. Bessey, R. Bruce Prime and A. K. Sircar, in: E. A. Turi (Ed.), Thermal Characterization of Polymeric Materials, $2^{\text {nd }}$ edition, Academic Press, California, USA, 1981, p1295, 1443 and 1791.

25. G. Chiodelli, P. Ferloni, A. Magistris, M. Sanesi, Solid State Ion. 28-30 (1988) 1009.

26. L. B. Weisfeld in: J. T. Lutz, R. F. Grossman, (Eds.), Polymer modifiers and additives, Marcel Dekker, Inc., New York, 2001, p 419.

27. C. Berthier, W. Gorecki, M. Minier, M. B. Armand, J. M. Chabagno and P. Rigaud, Solid State Ion. 11 (1983) 91.

28. A. M. Christie, L. Christie and C. A. Vincent, J. Power Sources 74 (1998) 77.

29. A. P. Karpinski, S. J. Russell, J. R. Serenyi, J. P. Murphy, J. Power Sources 91 (2000) 77. 
Fig. 1. Thermograms of (TMC) $)_{10} \mathrm{LiX}$ electrolyte compositions containing a) $\mathrm{Li} \mathrm{BF}_{4}$ and b) $\mathrm{Li} \mathrm{ClO}_{4}$

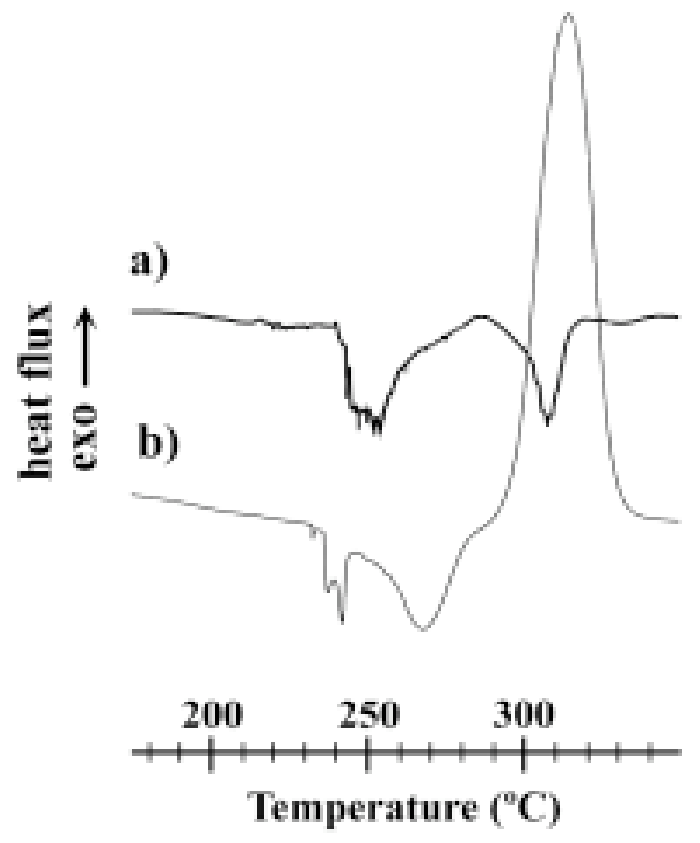

Fig. 2 a). Effect of electrolyte composition on (TMC) $)_{n}$ LiBF$_{4}$ electrolyte thermal stability

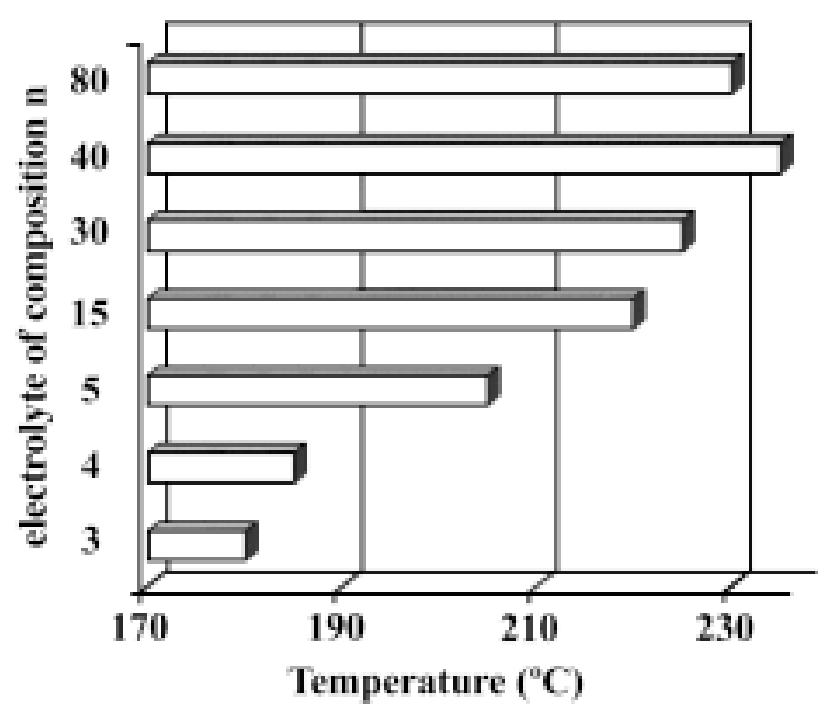


Fig. 2 b). Influence of electrolyte composition on the onset of glass transition

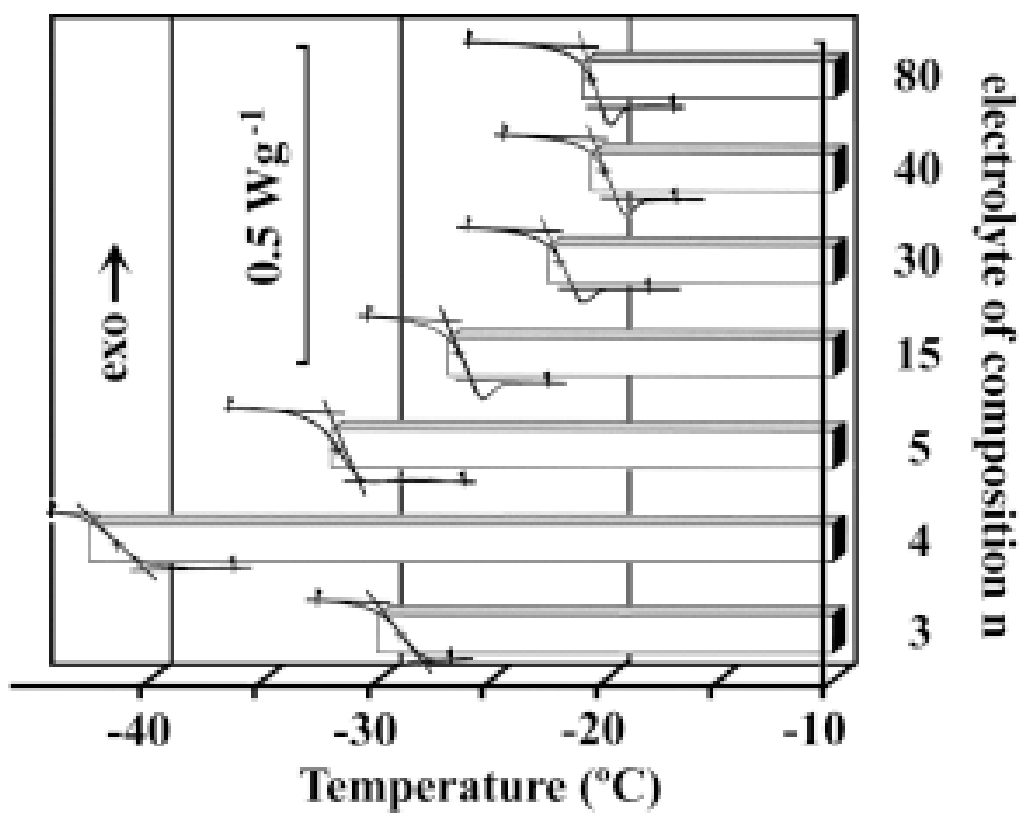

Fig. 3. Variation of conductivity with $1 / \mathrm{T}$ for selected $(\mathrm{TMC})_{\mathrm{n}} \mathrm{LiBF}_{4}$ electrolyte compositions $(\mathrm{n}=80 \bigcirc, 60 \Delta, 40 \diamond, 20 \square, 10 \bullet, 5 \mathbf{\square}, 4 \diamond$ and $3 \boldsymbol{\Delta})$

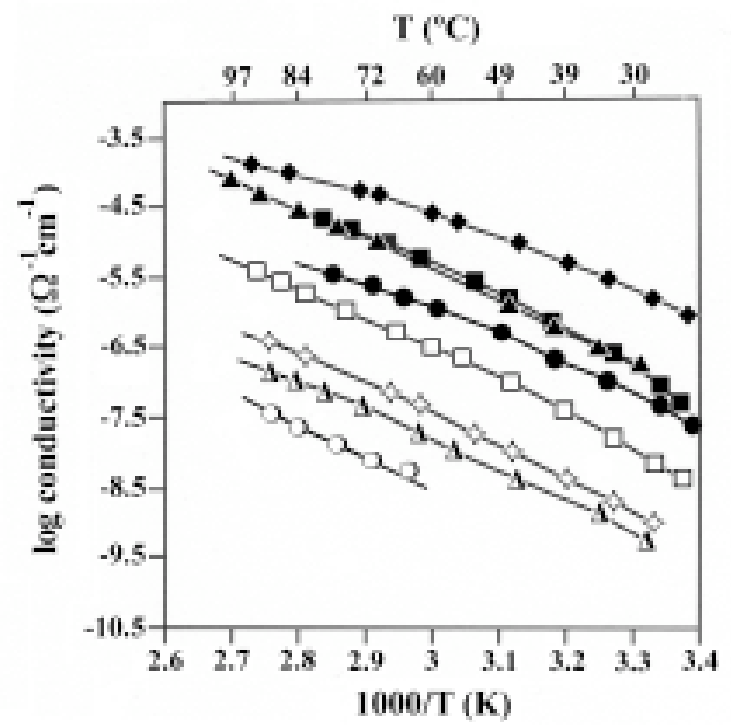


Fig. 4. Conductivity isotherms of $(\mathrm{TMC})_{\mathrm{n}} \mathrm{LiBF}_{4}$ electrolytes (at $40^{\circ} \mathrm{C} \boldsymbol{\square}, 55^{\circ} \mathrm{C} \bullet, 70^{\circ} \mathrm{C} \boldsymbol{\Delta}$ and $80^{\circ} \mathrm{C}$

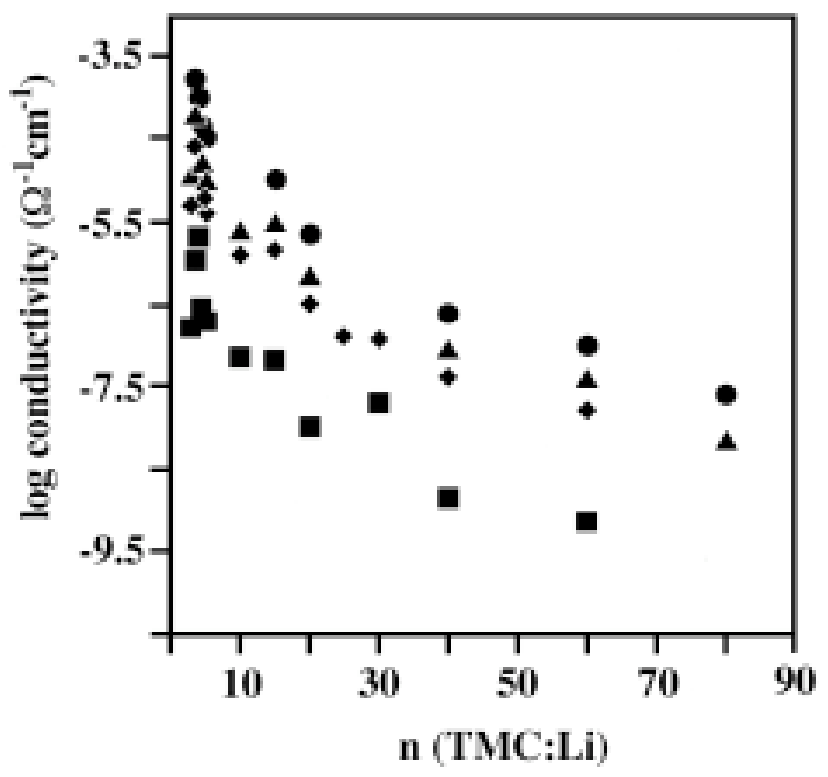

Fig. 5. Voltammogram of (TMC) $)_{4} \mathrm{LiBF}_{4}$ electrolyte at a $25 \mu \mathrm{m}$ diameter gold microelectrode vs $\mathrm{Li} / \mathrm{Li}^{+}$. Initial sweep direction is anodic. Sweep rate $200 \mathrm{mV} \mathrm{s}^{-1}$.

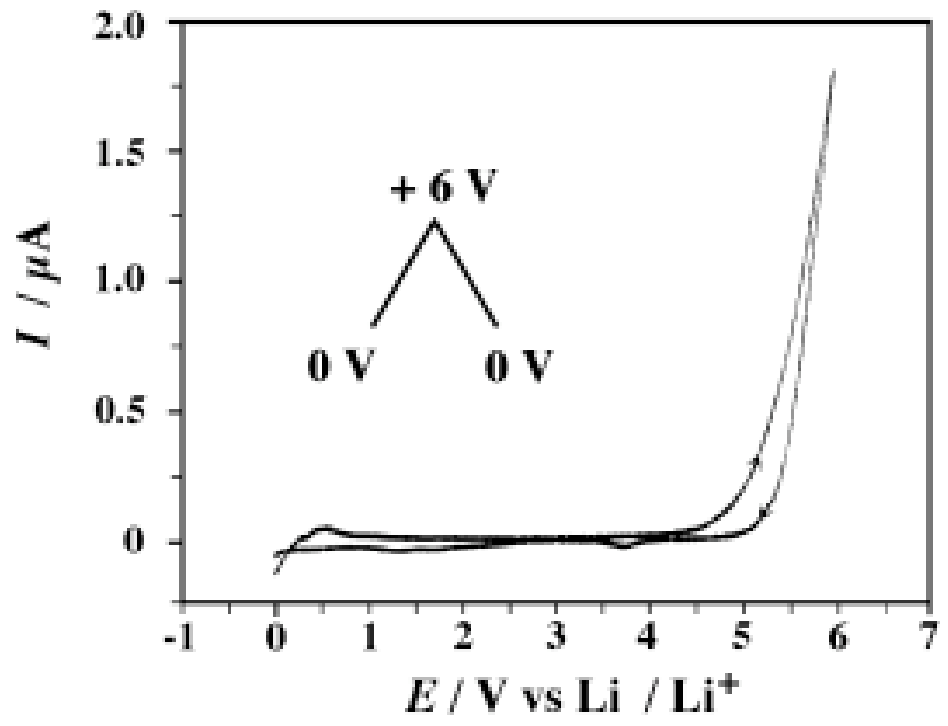


